\title{
DYNAMIC PERFORMANCE OF A CURVED CABLE-STAYED BRIDGE
}

\author{
James M W Brownjohn ${ }^{1}$, Jeffery Lee ${ }^{2}$, Bernard Cheong ${ }^{2}$ \\ ${ }^{1}$ Senior Lecturer $\quad{ }^{2}$ Former student \\ School of Civil and Structural Engineering, \\ Nanyang Technological University, \\ Nanyang Avenue, \\ Singapore 639798 \\ Fax (65) 7910676 \\ Tel (65) 7911744
}

\begin{abstract}
The dynamic behaviour of a $100 \mathrm{~m}$ span curved cable-stayed bridge constructed in Singapore has been studied by full-scale testing and analytical models. Comparison of test results and free vibration analyses show that modelling of the deck end fixity is an important factor while correct modelling of stay cables and stress-stiffening effects is not so important except for identifying cable modes with weak superstructure interaction which may appear in the measured response. Estimates of stay-cable tension obtained from inducing cable vibrations may be inaccurate unless the anchorage stiffness and mass distribution are well known. Despite its limitations the ambient vibration test technique is most appropriate for a structure of this size.
\end{abstract}

\section{KEYWORDS}

CABLE STAYED BRIDGE, FINITE ELEMENT ANALYSIS, STRUCTURAL DYNAMICS 


\section{INTRODUCTION}

Cable stayed bridges, are being built in more unusual styles for aesthetic as well as structural reasons ${ }^{1}$. As well as the more regular symmetric cable stayed bridges with spans approaching $1 \mathrm{~km}$, the short asymmetric designs have interesting dynamic characteristics that repay investigation. Some of the more recent unusual designs include the Alamillo (Seville) bridge ${ }^{2}$, the Itenhard pedestrian bridge (Switzerland) ${ }^{3}$ and the Rhine bridge ${ }^{4}$, all of which have been the subject of dynamic testing and/or modelling. Among the more unusual designs is the Safti Link Bridge ${ }^{\mathbf{5}}$ which is a landmark in Singapore and was studied to evaluate the bridge itself as well as the means of testing and analysing it.

\section{BRIDGE DESCRIPTION}

The Safti Link Bridge (Figure 1) comprising a curved concrete box deck and a single independent offset pylon is located in western Singapore and provides vehicle access across a major expressway, linking Pasir Laba Camp and the Safti Military Institute.

Figure 2 shows schematic plan and elevation views of the bridge. The arc of the curved deck along the centreline spans $100 \mathrm{~m}$ between abutments and the total width of the traffic lanes is $8 \mathrm{~m}$ with two $2 \mathrm{~m}$ walkways. The deck has a $180 \mathrm{~m}$ radius of curvature to the centreline where nine 'bridge stay' cables are attached at $10 \mathrm{~m}$ centres, supporting the deck from the pylon which is held in position by three pairs of 'back stay' cables.

Figure 3 shows details of the concrete deck girder which comprises a central $2 \mathrm{~m}$ deep box with 'wing-tip' girder plus $3 \mathrm{~m}$ of cantilever on each side. Prestressed $0.3 \mathrm{~m}$ transverse diaphragms are provided at $5 \mathrm{~m}$ intervals to improve torsional rigidity, to resist transverse bending and to transfer load between the stay cable anchorage and the bridge deck. Loads are also transferred from the deck to the bridge stays by two $0.35 \mathrm{~m}$ thick webs along the centre of the girder. The post-tensioned box-section deck was cast in-situ with grade 80 concrete for durability considerations although grade 50 was assumed in the design.

For greater stability the deck is fixed at the abutments, which rest on a row of $1.4 \mathrm{~m}$ diameter bored piles. A system of $1.25 \mathrm{~m}$ by $1.25 \mathrm{~m}$ ground beams links the back stay anchorages to each other and the base of the octagonal tapered pylon (Figure 4). Five $1.55 \mathrm{~m}$ diameter bored piles support the pylon footing, while back stay anchorages combine an arrangement of small bored piles and ground anchors. Pile depths vary according to conditions but are a minimum $25 \mathrm{~m}$ for the pylon base, $16.5 \mathrm{~m}$ for abutments. Together with the back stays, the pylon, ground beams and ground anchors form a separated support structure connected to the deck via the bridge stays. Bridge stay 4 is vertical, locating its termination in the pylon approximately $30 \mathrm{~m}$ above its anchorage in the deck, with the pylon continuing to a height 42.55 above its base. 
All bridge stays were stressed at anchor blocks located in the bridge deck after construction of the deck to progressively lift it clear of the construction supports, while the back stays were stressed from the ground anchor caps. Bridge stays use either 43 $15 \mathrm{~mm}$ diameter strands of steel cable or 39 strands (for the shorter stays) while back stays have 65 strands. Each strand comprises seven $5 \mathrm{~mm}$ diameter galvanized wires and is individually protected by a high-density polyethylene (HDPE) sheath and anti-corrosion compound filling. In each cable the bundle of strands is clamped together with spacers inside a HDPE duct, with the voids between sheaths and duct filled with polyurethane grout.

\section{FINITE ELEMENT MODELS}

The structure was modelled as a composition of substructures as follows:

(i) A box-type 'deck girder' with diaphragms, modelled with conventional three dimensional (3-D) beam elements, forms a 'spine' for the deck, intended to incorporate all the bending, torsional and inertial properties of the box-deck.

(ii) Pylon, ground beams and back stays (numbered a, b and c) are modelled as beam elements while foundation restraints are modelled as 3-D truss elements acting as springs. The final values for the spring elements representing the foundations are significantly higher than the original values used by the consultants, and essentially fix the support points in translation.

(iii) Bridge stays (numbered 1 to 9 ) are modelled as 3-D beam elements.

(iv) A system of 'pseudo-beams' and quadrilateral shell elements models the notional traffic lanes, all having zero density and relatively low stiffness. The function of these elements in the static load case analyses by the consultant was to transfer vehicle loading to the spine beam, but these elements also help to visualise the dynamic behaviour of the deck which is not clear from the linear representation of the box deck girder. They also affect the deck fixity at the abutments.

Concrete with elastic modulus 35GPa was assumed for the deck girder and pylon, with $1 \%$ of the nominal $31 \mathrm{GPa}$ stiffness used for shell and pseudo-beams. The cables were assumed to have moduli in the range 192-195GPa.

Figure 5 shows the 'reference' finite element model incorporating all the above elements. The spine of girder elements, the diaphragms and one set of shell elements (bounded by pseudo beams) are highlit. Boundary conditions are indicated as piles.

The cable tensions were initially expected to have a significant effect on the bridge dynamic properties via geometric stiffness effects thus the free vibration analyses required inclusion of the stress-stiffening due to the cable tensions. For the computer code used (ANSYS) these tensions have to be predetermined in a prior static analysis and then carried over into the global stiffness matrix for dynamic analysis. The prior 
static analysis could begin with a neutral unloaded condition and impose a gravity load but this would result in initial bending stresses in the deck and low cable tensions. Instead, initial tensile strains estimated from the design tensions were set in the cables with the aim of producing neutral deck stresses and correct cable tensions, emulating the actual construction process of lifting the deck up off the formwork. In fact it was necessary to iterate with different initial strains to generate close approximations to the design tension values in the cables for the dynamic analysis. The free vibration analyses then used a linearised stiffness matrix representing the dead load condition, since the small vibrations due to normal service loads do not justify non-linear dynamic analyses.

The abutment restraints due to the piles were initially modelled with design stiffness for translation and rotation but it became clear that infinite translational stiffness (i.e. restrained translation) gave better representation of deck modes as compared to observed shapes and so was adopted in all the models. At the same time the rotational restraints were released at the deck abutments.

As well as the 'reference model', other variants were considered:

Deck girder: variant in which the low stiffness deck shell and pseudo beams are not included and the deck is fully fixed to ground at the abutments,

Deck only: variant in which the bridge stays are detached from the deck and the pylon/back stay/ground beam system is ignored,

Multi-element cable: variant in which two of the bridge stays are modelled with five elements rather than one single element and

No geometric stiffness: with tension in cable and/or compression in pylon ignored.

\section{FREE VIBRATION MODES FOR FINITE ELEMENT MODELS}

Reference model: Table 1 gives in tabular form the mode type and natural frequencies for the reference model (Figure 5). The descriptions given in column 2 summarise the type of dominant vibration e.g. VA1 denotes a mode that is primarily vertical movement of an antisymmetric nature of the simplest form. For a simply supported beam, vibration modes appear in a distinct sequence: VS1 (no stationary points), VA1 (one stationary point), VS2 (two stationary points), VA2 (three stationary points) etc. For this bridge the terms 'symmetric' and 'antisymmetric' are really misnomers due to lack of symmetry in the structure and the resulting modes but they indicate the type of mode. Also, mode types reappear e.g. at least two of the first 20 modes e.g. 2,4 and 5 could be described as VA1.

Three-dimensional (3D) mode shape plots show that significant pylon bending features in all the modes; modes 6 and $12-15$ are almost pure pylon $(\mathrm{P})$ modes. Modes $6,8,9,13$ and 19 feature pylon bending with a mode shape resembling static deflection 
of a propped cantilever, while the lower modes feature the simpler deflected shape with largest deflection at the tip.

Due to the curved deck it is difficult to interpret the deck behaviour from 3D plots, so 'developed views' of the modes are shown in column 3 of Table 1 . The developed views were obtained according to the conventions shown in Figure 6. Vertical components $\mathrm{U}_{\mathrm{y}}$ of the modes for positions on east and west parapets, plus horizontal components on the east parapet resolved in the radial direction are plotted together in plane, normalised to unit value of vertical displacement at $4 \mathrm{~W}$. The plots include values for $0 \mathrm{E}$ to $10 \mathrm{E}$ (11 vertical and 11 lateral) plus $0 \mathrm{~W}$ to $10 \mathrm{~W}$ (11 vertical) going from left to right.

Fundamental symmetric torsional and lateral modes (TS1 and LS1) are found below $4 \mathrm{~Hz}$ but the plots show that with few exceptions, a significant element of torsion is present in 'vertical' modes. Lateral modes are relatively few and usually appear together with deck torsion. The comparison of modes generated by the different models, supported by inspection of the mode shapes with the above method, provides some useful observations.

Deck girder: For the deck, only the deck girder with diaphrams, item (i) in Figure 5 are included. The modes generated by this variant have generally different character from the reference model but for comparable modes, vertical and lateral vibrations appear at higher frequencies (10-20\% higher, due toadditional rotational fixity at the abutments) while torsional frequencies are similar. The deck girder model would be a good subject for systematic adjustment of deck restraint stiffness parameters.

Deck only: Only the deck component items (i) and (iii) in Figure 5 plus abutment piles are included in this model, for which the lower frequency vertical modes are of course very different but the lateral and torsional modes (which do not have significant pylon movement) are similar to the reference model. It may be supposed that a representation of vertical behaviour could be obtained by introducing springs at the bridge stay anchorages.

Multi-element cable: In this model, selected bridge stays (nos. 6 and 9, indicated in Figure 5) were modelled using five elements instead of one making it possible to see that modes shown in Table 1 have significant cable vibrations. In addition, four completely new symmetric cable modes, two for each cable, were generated as shown in Table 2. These four modes featured small but noticeable vertical deck deflection.

Representation of stay cables as multiple elements results in a larger, more complex FE model with a high proportion of cable modes in the eigensolution, so that many more modes have to be generated to produce the same number of deck modes. A good example of such a representation is given in a study of the effect of stay cable repairs on the Polvera Creek Viaduct ${ }^{9}$. 
No geometric stiffness: The reference models was run on different software (SAPIV), with direct modifications to the global stiffness matrix reflecting the tensions in the cables and compression in the pylon. Setting cable tensions to zero resulted in reductions of $2 \%$ and $4 \%$ in frequencies for modes VA1 and VS1 and less than $1 \%$ in other modes. Setting pylon compression to zero resulted in increases of aproximately $2 \%$ for the same modes and negligible effect on other modes.

\section{SITE TESTING}

A dynamic site test ${ }^{10}$ of the bridge was conducted over a three day period with the aim of determining the character of the three-dimensional vibration modes (shapes and frequencies) up to approximately $10 \mathrm{~Hz}$. Access to the pylon proved to be impossible so measurements were made by placing accelerometers only on the deck, at locations $0 \mathrm{E}$ to $10 \mathrm{E}, 0 \mathrm{~W}$ to $10 \mathrm{~W}$ and $4 \mathrm{C}$ (positions indicated in Figure 6), and also on bridge stay and back stay cables. Two techniques were employed: ambient vibration testing (AVT) ${ }^{11}$ which relies on wind, traffic and other 'natural', ucontrollable force inputs to excite vibration modes, and forced vibration testing (FVT) ${ }^{\mathbf{1 2}}$ in which vibration is induced via a measurable force input, in this case an impact hammer.

A set of eight Allied Signal QA-700 accelerometers were used and the low-pass filtered signals were recorded on a portable computer via a PCMCIA analog to digital converter (ADC) card. A 12 pound instrumented sledgehammer was used for the FVT, and for cable measurements. All equipment was battery operated.

For measurement of vertical components of modes three accelerometers sensing vertically $\left(\mathrm{U}_{\mathrm{y}}\right)$ were placed at locations $4 \mathrm{E}, 4 \mathrm{C}$ and $4 \mathrm{~W}$. Four more accelerometers were placed in east/west pairs at other locations to monitor the bridge vertical response in a series of five recordings covering the length of the deck e.g. $0 \mathrm{E}, 0 \mathrm{~W}, 1 \mathrm{E}$ and $1 \mathrm{~W}$ then moving to $2 \mathrm{E}, 2 \mathrm{~W}, 3 \mathrm{E}$ and $3 \mathrm{~W}$. For some of these recordings the response of bridge stay 3 , adjacent to location $3 \mathrm{C}$ was also measured to check coherence with deck vibrations. Ambient vibrations were excited by wind, occasional passing of trucks, buses or cars, by jumping or by marching soldiers. Forced vibrations with measurable input were due to vertical hammer impact between locations $3 \mathrm{E}$ and $4 \mathrm{E}$.

For measurements of lateral components of modes the accelerometers were placed along the east parapet, sensing horizontally in the radial direction $\left(U_{r}\right)$ in two recordings covering all the measurement points. Again, vibrations were excited by wind or traffic as well as by hammer impact.

\section{DATA PROCESSING}

For each combination of positions a data set of between 16 and 48 AVT records of 1024 samples digitised at $40 \mathrm{~Hz}$ per channel was obtained. By RMS averaging within 
each data set and comparing signal amplitudes at the identified natural frequencies against values at location $4 \mathrm{~W}$ a set of mode shapes was constructed for each possible natural frequency. For each combination of locations a set of 8-16 FVT records was also obtained for checking against the AVT results.

For response in the linear range with proportional damping the modes of vibration are real and independent and the dynamic response at a point can be regarded as the sum of response in all modes due to forces at all nodes. Considering a discretised model, if a time-varying force $p_{j}(t)$ is applied at degree of freedom (DOF) $j$ and the acceleration response $\ddot{x}_{k}(t)$ is measured at DOF $k$ then the ratio of output and input is defined as the frequency response function (FRF)

$$
\mathrm{H}_{\mathrm{jk}}(\omega)=\frac{\ddot{X}_{\mathrm{k}}(\omega)}{\mathrm{P}_{\mathrm{j}}(\omega)}=\sum_{\mathbf{r}} \frac{-\omega^{2} \varphi_{\mathrm{rj}} \varphi_{\mathrm{rk}}}{\mathrm{m}_{\mathrm{r}}\left(-\omega^{2}+\omega_{\mathrm{r}}^{2}+2 \mathrm{i} \xi_{\mathrm{r}} \omega_{\mathrm{r}} \omega\right)}
$$

where $\ddot{\mathrm{X}}_{\mathbf{k}}(\omega)$ and $\mathrm{P}_{\mathrm{j}}(\omega)$ are the Fourier transforms of $\ddot{\mathrm{x}}_{\mathbf{k}}(\mathrm{t})$ and $\mathrm{p}_{\mathrm{j}}(\mathrm{t})$ respectively, $\omega$ is circular frequency (radians per second), $\omega_{\mathrm{r}}$ is natural frequency for mode $\mathrm{r}$, and $\xi_{\mathrm{r}}$ is fraction of critical damping. Mode shape ordinates at $\mathrm{j}$ and $\mathrm{k}$ for mode $\mathrm{r}$ are denoted $\varphi_{\mathrm{rj}}, \varphi_{\mathrm{rk}}$ and $\mathrm{m}_{\mathrm{r}}=\varphi_{\mathrm{r}}^{\mathrm{T}} \mathbf{M} \varphi_{\mathrm{r}}$ is the modal mass using discrete mass distribution described by the mass matrix $\mathbf{M}$.

Equation (1) defines a form of FRF having units mass ${ }^{-1}$ and termed 'inertance'. If the input force can be measured the FRF can be used directly to recover values of $\omega_{\mathrm{r}}, \zeta_{\mathrm{r}}$. For excitation at a single point $\mathrm{j}$ as in equation (1), for a particular mode $\mathrm{r}$ all parameters except the mode shape ordinate $\varphi_{\mathrm{rk}}$ are constant so mode shape ordinates can be obtained from a set of measurements varying $\mathrm{k}$. Modal mass $\mathrm{m}_{\mathrm{r}}$ can also be recovered.

For multi-point excitation e.g. wind the response at $\mathrm{k}$ is the sum of responses to all inputs $\mathrm{j}$

$$
\ddot{\mathrm{X}}_{\mathbf{k}}(\omega)=\sum_{\mathbf{j}} \mathrm{P}_{\mathrm{j}} \mathrm{H}_{\mathrm{jk}}(\omega)=\sum_{\mathbf{j}} \sum_{\mathbf{r}} \frac{\mathrm{P}_{\mathrm{j}}(\omega) \varphi_{\mathrm{rj}} \varphi_{\mathrm{rk}}}{\mathrm{m}_{\mathrm{r}}} \mathrm{H}_{\mathbf{r}}(\omega)
$$

where $\mathrm{H}_{\mathrm{r}}(\omega)=-\omega^{2} /\left(-\omega^{2}+\omega_{\mathrm{r}}^{2}+2 \mathrm{i}_{\mathrm{r}} \omega \omega_{\mathrm{r}}\right)$.

For response due to light wind the inputs $\mathrm{P}_{\mathrm{j}}(\omega)$ will be random but should average to slowly varying functions of frequency so that over a long enough period, $\ddot{\mathrm{X}}_{\mathrm{k}}(\omega)$ is effectively $\mathrm{H}_{\mathrm{r}}(\omega)$ multiplied by an unknown scale factor and phase angle. Hence $\omega_{\mathrm{r}}, \zeta_{\mathrm{r}}$ can also be estimated from the measured response alone by curve fitting to the shape of $\left|\mathrm{H}_{\mathrm{r}}(\omega)\right|$ around each resonance, provided the frequencies are well separated. 
Recovery of mode shapes is not subject to assumptions about the input (forcing functions). Taking the ratio of responses at two positions, $\ddot{X}_{m}(\omega)$ and $\ddot{X}_{n}(\omega)$ given by (2) at $\omega=\omega_{\mathrm{r}}$, provided damping in other modes $(\neq \mathrm{r})$ is low, the contributions from other modes are small compared to that from mode $r$ and the terms $\mathrm{P}_{\mathrm{j}}(\omega) \varphi_{\mathrm{rj}} / \mathrm{m}_{\mathrm{r}}$ cancel so that

$$
\ddot{\mathrm{X}}_{\mathrm{m}}(\omega) / \ddot{\mathrm{X}}_{\mathrm{n}}(\omega) \approx \varphi_{\mathrm{rm}} / \varphi_{\mathrm{rn}} \ldots \ldots \ldots \ldots . \ldots \ldots \text { ) }
$$

which should be a positive or negative ratio that can be recovered directly from the amplitude ratio and phase angle $\left({ }^{\circ} 0\right.$ or $\left.180^{\circ}\right)$ between the two responses. If one position $\mathrm{n}$ is not changed the mode shapes can be obtained directly by varying position m. The principle also applies to single input excitation (e.g. hammer impact) or a moving vehicle. The vehicles observed crossing the bridge had mass less than $1 \%$ of the mass of the deck so there would have been negligible effect on the dynamic behaviour.

In practice since the time histories are sampled and finite, the Fourier transforms are samped and finite, so the discrete (fast) Fourier transform or FFT is used, having values at discrete frequencies corresponding to amplitudes of the components of the signal at these discrete frequencies. The graph of values of magnitude of the FFT as a function of frequency is referred to here as the auto power spectrum.

\section{EXPERIMENTAL RESULTS}

Figure 7a shows typical auto power spectra for vertical response at $4 \mathrm{E}$ due to light wind with many peaks in the range $0-6 \mathrm{~Hz}$. Strongest vertical response occurred at $1.18 \mathrm{~Hz}$ (zero node symmetric mode, VS1) and $2.76 \mathrm{~Hz}$ (single node antisymmetric mode VA1) but numerous other modes occurred in this range. Figure $7 \mathrm{~b}$ shows response at the same position for a period with a truck passing over the deck strongly exciting the modes at $2.76 \mathrm{~Hz}$ and $4.61 \mathrm{~Hz}$. Figure $7 \mathrm{c}$ shows vertical response due to hammer excitation with fewer peaks in the low frequency range but several strong peaks at higher frequencies.

As expected the AVT lateral response was much weaker than the vertical response, except for the mode at $3.08 \mathrm{~Hz}$, with, in general, positive (upwards) movement at $4 \mathrm{E}$ at the same time as negative (inwards) movement.

Figure 8 shows the imaginary part of the FRF for lateral response obtained by FVT, containing only a few modes; strongest lateral response from $0-10 \mathrm{~Hz}$ occurred at $3.08 \mathrm{~Hz}$ (zero node symmetric mode LS1) and $6.1 \mathrm{~Hz}$ (single node antisymmetric mode LA1). The units are (mass) $)^{-1}$ where $1 \mathrm{Mg}=1000 \mathrm{~kg}$ or 1 metric tonne $(\mathrm{t})$. Without dynamic amplification a rigid mass equivalent to the $1500 \mathrm{t}$ deck would have a constant FRF value of $0.67 \times 10^{-3} \mathrm{t}^{-1}$. FVT proved to be more effective for lateral measurements due to the weaker ambient response but to minimise the effect of the 
ambient 'noise', sharply decaying exponential windows were applied resulting in the broad peaks shown in Figures 7c and 8. Experimental transfer function data could not be obtained for vertical modes because the ambient vertical response is at least an order of magnitude stronger. A structure of this size is probably the limiting case for FVT with a hammer.

The ten strongest measured modes are shown in Figure 9, with the developed mode shape views using the same convention as in Table 1. Values of experimental and FE (reference model) are given and the experimental mode shapes are compared to the FE mode shapes using Modal Assurance Criterion (MAC) values for FE reference model modes having the best match to the measured modes.

The MAC for mode $r$ is analogous to a correlation coefficient and is defined as

$$
\mathrm{MAC}=\left[\sum_{\mathrm{j}=1}^{\mathrm{j}_{\max }} \varphi_{\mathrm{rj}} \delta_{\mathrm{rj}}\right]^{2} / \sum_{\mathrm{j}=1}^{\mathrm{j} \max } \varphi_{\mathrm{rj}}^{2} \times \sum_{\mathrm{j}=1}^{\mathrm{j}_{\max }} \delta_{\mathrm{rj}}^{2} \ldots \ldots \ldots \ldots \ldots
$$

where $\delta_{\mathrm{rj}}$ is the mode shape ordinate from the FE model and $\mathrm{j}$ max is the number of corresponding positions on the model and prototype where mode shapes are evaluated and measured.

The corresponding mode numbers for the reference model (Table 1) are indicated e.g. ref: $1(1.34 \mathrm{~Hz})$ corresponds to measured modes at $1.18 \mathrm{~Hz}$ and $1.52 \mathrm{~Hz}$, the former giving closer agreement.

Generally, the measured vertical modes correspond well with the modes predicted by the reference model, those measured having slightly lower frequencies than computed. Other modes are not so easily compared; torsional modes occur at higher frequencies and lateral modes occur at lower frequencies compared to FE values.

Mode LS1 $(3.08 \mathrm{~Hz})$ has a strong torsional component in the opposite sense to that for the $\mathrm{FE}$ version $(3.784 \mathrm{~Hz})$ while antisymmetric torsion and antisymmetric lateral motion are only found together and in one single measured mode (LA1, 6.1 Hz). This mode has been compared to two FE modes: 11 (torsion only) and 17 (mainly lateral). MAC values obtained for comparison of LS1 and LA1 with FE lateral modes use only the lateral displacement mode shape values.

Modes at $10.25 \mathrm{~Hz}(\mathrm{VS} 3)$ and $11.63 \mathrm{~Hz}$ (TA2) were also identified but could not be compared to any of the lowest 20 reference model modes.

Using the design values of pile stiffness in analysis with the reference model led to significant deflections at the abutment that were not observed in the measurements. In fact vertical and lateral mode shapes show zero response at the abutments, consistent with translational restraint. 
In addition to the modes shown in Figure 9 a strong response was observed at a frequency of $2.15 \mathrm{~Hz}$ when a column of approximately 100 soldiers marched over the bridge. Figure 10a shows the measured response and Figure 10b shows the response during transit of a heavy vehicle with a dominant frequency of $2.76 \mathrm{~Hz}$. Both responses, which are shown bandpass filtered to remove the weaker responses outside the $2 \mathrm{~Hz}-3 \mathrm{~Hz}$ range, have similar magnitude but the response at $2.15 \mathrm{~Hz}$ was only observed on the one occasion whereas the mode at $2.76 \mathrm{~Hz}$ was also excited strongly without the truck. Presumably $2.15 \mathrm{~Hz}$ is the marching footfall frequency yet there is no evidence of harmonics of this frequency; in fact the response in Fig. 10a degenerates into the $2.76 \mathrm{~Hz}$ mode after 35 seconds. Assuming an average load per person to have a fundamental sinusoidal component of $0.3 \mathrm{kN}$, and that the response is not resonant but is controlled by the deck mass leads to a crude estimate of resulting acceleration as $0.02 \mathrm{~m} / \mathrm{s}^{2}$ which is consistent with the observed response.

More deck vibration modes were measured than predicted; apart from the duplication of VS1, a number of smaller peaks were observed in the AVT vertical acceleration auto power spectra (Figure 5a). Study of modes from the multi-element cable model suggests that these may be weak deck participation of cable vibrations. For this reason and to provide an estimate of stay cable tensions to cross-check with the design values, a series of measurements was made on the back stays and bridge stays.

\section{STAY CABLE BEHAVIOUR}

In FE modelling of stay cables it may often be adequate to represent the axial stiffness of a cable by a single element with a steel modulus that may be reduced to account for the necessary vertical sag.

The FE models, except deck only, represented the cables in terms of the axial area of steel and pinned terminations at the extreme ends. For the prototype structure the cable mass is increased by the HDPE sheathing and grout and anti-corrosion compound and there appears to be significant lateral restraint due to the anchorages continuing for one or two metres from the cable tensioning surface. To model the real behaviour of the cable would require accurate determination of the mass, lateral restraint and flexural resistance of the arrangement.

Initially it was assumed that the cables could be approximated as pin-ended wires of length $L$, mass per unit length $m$ and tension $T$ having natural frequencies

$$
f_{n}=\frac{n}{2 L}\left(\frac{T}{m}\right)^{1 / 2}
$$

for the fundamental mode $(n=1)$ and $n$th harmonics. From this approximation it was intended to estimate the actual cable tensions for use in the FE model. 
With the expectation that frequencies would differ slightly in the vertical and horizontal directions, which was borne out by multi-element cable FE predictions shown in Table 2, two accelerometers, set in vertical and horizontal directions were fixed to the lower part of each of the 15 stay cables in turn. For each cable, vibrations were induced by sledgehammer blows. Whether the blows were aligned vertically, horizontally or a bit of both, frequencies determined for each direction were indistinguishable and followed a clear pattern of equi-spaced harmonics usually with a weak fundamental, due to the difficulty in measurement and excitation beyond the first one or two metres from the cable anchorage. Also, for the back stays which are arranged as pairs sharing the same anchorages it was found that vibration excited in one cable did not produce any response in the adjacent non-excited cable.

Figure 11 shows the transient acceleration time history and the corresponding auto power spectrum for the longest bridge stay, back stay cable a1. This is the nearest and highest cable in the upper view of Figure 1, and one of the cable pairs denoted a in Figure 2. The equal spacing of harmonics in Figure 11 suggests minimal end stiffness effects.

Table 3 shows cable tensions estimated using Equation 5 based on the fundamental frequencies. The stay cables are denoted sc1 ...sc 9 , the back stays as bs a1 ...bs c 2 . The columns labelled 'Simple estimate' account only for steel and take the full cable length. These estimates were somewhat different to the design values so 'Refined estimates' were determined including the mass of the grout and ducting, usually doubling the effective mass, and reducing the length of the cable by the estimated length of cable embedded in concrete or otherwise restrained.

The final column gives the actual cable tensions. These were checked by the post-tensioning contractor just after the measurements and were found to be close to the design values. It remains mysterious and cautionary that tension estimation by vibration measurements can be so inaccurate.

One benefit of measuring the stay cable frequencies was that some weak peaks identified in vertical ambient vibrations such as Figure 7a e.g. $1.56 \mathrm{~Hz}, 1.99 \mathrm{~Hz}, 2.17 \mathrm{~Hz}$, $2.38 \mathrm{~Hz}, 2.48 \mathrm{~Hz}$ were shown to occur at or near stay cable fundamental frequencies and are probably deck participation in cable modes. Some of the stronger modes i.e. $2.76 \mathrm{~Hz}, 3.00 \mathrm{~Hz}$ and $3.6 \mathrm{~Hz}$ also occurred at stay cable frequencies.

From study of contemporary deck and cable vibrations due to light winds it is possible to see significant coherence between deck and cable at frequencies given above. For the strongest deck mode (VA1) the cable and deck vibrations are the same order of magnitude suggesting a rigid body interaction, while for the symmetric cable modes the cable vibrations are at least an order of magntude stronger than the deck. 


\section{CONCLUSIONS}

Comparison of analytical (finite element) model predictions and full-scale measurements on the Safti Link Bridge show that the best match of measured modes is with a finite element (FE) model that uses a deck girder to represent deck bending and torsional properties together with a low stiffness deck system to effect restraint at the abutments. Vertical and lateral modes are observed in the prototype at slightly lower frequencies than predicted while the reverse is true for torsional modes.

Due to the lack of symmetry in the prototype, vertical or lateral modes invariably have a strong element of torsion. The participation of the pylon could not be studied experimentally but FE studies suggest a number of pylon-only modes in addition to pylon participation in predominantly vertical deck modes.

For the prototype testing some useful lessons were learnt:

The ambient vibration test (AVT) technique proved to be more useful than forced vibration due to the low signal to noise ratio for vibrations forced by hammer impact. Even so it was possible to recover useful information from forced lateral vibrations due to the much weaker lateral ambient response. The mass of the bridge puts it at the limit of capability for hammer testing.

Measurement of stay cable vibrations was not an accurate means of assessing cable tension, but it did support observations from FE modelling with multi-element cables that weak deck modes can occur at stay cable fundamental frequencies, and such modes were found in the measured deck response.

\section{ACKNOWLEDGEMENTS}

The authors would like to thank Er Tan See Chee of TY Lin (South East Asia) Pte. Ltd for his help and interest in the research and Ms Stella Tan of Land Estates Organisation and staff of Safti for their assistance with the experimental work. 


\section{REFERENCES}

1 Leonhardt, F., Bridges -aesthetics and design. Deutsches Verlagsanstalt, 1982.

2 Casa, J. R., 'Full-scale dynamic testing of the Alamillo cable-stayed bridge in Sevilla (Spain).' Earthquake Engineering and Structural Dynamics, 1995, 24 $35-51$.

3 Deger, Y., Felber, A., Cantieni, R., de Smet, C. A. M., Dynamic modeling and testing of a cable stayed pedestrian bridge.' Proceedings, 14th International Modal Analysis Conference, Michigan, USA, February 1996.

4 de Smet, C. A. M., Felber, A. J., Cantieni, R., Kramer, C., 'Ambient vibration study of the new Rheinbridge for Highway N4.' Proceedings, 14th International Modal Analysis Conference, Michigan, USA, February 1996.

5 Tan, S. C., 'Safti Link Bridge. Design and construction.' Defence Technology Group Seminars Series, 1995-1996, MINDEF Singapore.

6 Cheong, K. C., 'Dynamic analysis of a cable-stayed bridge.' School of Civil and Structural Engineering, Nanyang Technological University, April 1997.

7 ANSYS52 Users Manual Rev 5.2. Swanson Analysis Systems, 1995.

8 Bathe, K. J., Wilson, E. L., Peterson, F. E., 'SAPIV structural analysis program for static and dynamic response of linear systems.' Report EERC 73-11, Berkeley, USA, 1973.

9 Gentile, C., Martinez y Cabrera, F., 'Dynamic investigation of a repaired cable-stayed bridge.' Earthquake Engineering and Structural Dynamics 1997, 26, 41-60.

10 Lee, H. J., 'Dynamic testing of a cable-stayed bridge.' School of Civil and Structural Engineering, Nanyang Technological University, April 1997

11 Udwadia, F. E., Trifunac, M. D., 'Ambient vibration tests on full-scale structures.' Proceeding, 5th World Conference on Earthquake Engineering, 1974, Vol. 2, Rome, 1430-1439.

12 Pavic, A., Waldron, P., 'Guidelines on modal testing of full-scale concrete floors using instrumented hammer impact excitation.' Structural Assessment. The Role of Large and Full-Scale testing. City University, UK, 1-3 July 1996.

13 Svensson, H. S., Jordet, E., 'The concrete cablestayed Helgeland Bridge in Norway.' Civil Engineering, Proceedings, Institution of Civil Engineers, 1996, 114, 54-63 and discussion, 1997, 120, 83. 


\section{LIST OF SYMBOLS}

E Elastic Modulus

$f \quad$ natural frequency

$\mathrm{H}_{\mathrm{jk}}(\omega)$ frequency response function (FRF) between positions $\mathrm{j}$ and $\mathrm{k}$

$\mathrm{H}_{\mathrm{r}}(\omega)$ dynamic amplification factor for mode $\mathrm{r}$

j position of force input

$\mathrm{k}$ position of acceleration response measurement

$L \quad$ Length (of cable)

$\mathrm{m}, \mathrm{n}$ positions for response measurements

M mass matrix

$\mathrm{m}_{\mathrm{r}} \quad$ modal mass for mode $\mathrm{r}$

$m$ mass per unit length of cable

$n \quad$ order of vibration harmonic

$\mathrm{P}(\omega)$ Fourier transform of force input $\mathrm{p}(\mathrm{t})$

r mode number

$T \quad$ Cable tension

$\ddot{\mathrm{X}}(\omega)$ Fourier transform of acceleration response $\mathrm{x}(\mathrm{t})$

$\delta_{\mathrm{rj}} \quad$ mode shape ordinate, mode $\mathrm{r}$ position $\mathrm{j}$, from finite element model

$\varphi_{\mathrm{rj}}, \quad$ mode shape ordinate, mode $\mathrm{r}$ position $\mathrm{j}$, from experimental data

$\omega_{\mathrm{r}} \quad$ (cricular) natural frequency, mode $\mathrm{r}$

$\zeta_{\mathrm{r}} \quad$ fraction of critical damping, mode $\mathrm{r}$ 
Table 1 Vibration modes predicted by reference FE model (Figure 5)

\begin{tabular}{|c|c|c|c|}
\hline Mode & Type & Developed mode & frequency \\
\hline 1 & VS1 & & $1.344 \mathrm{~Hz}$ \\
\hline 2 & VA1 & & $.883 \mathrm{~Hz}$ \\
\hline 3 & TS1 & …………… & $2.596 \mathrm{~Hz}$ \\
\hline 4 & VA1 & $\ldots$ & $2.931 \mathrm{~Hz}$ \\
\hline 5 & $\mathrm{VA} 1+\mathrm{P}$ & Non & $3.214 \mathrm{~Hz}$ \\
\hline 7 & LS1 & $\cdots \cdots$ & $3.784 \mathrm{~Hz}$ \\
\hline 8 & $\mathrm{P}+\mathrm{V}$ & & $910 \mathrm{~Hz}$ \\
\hline 9 & $\mathrm{P}+\mathrm{VS} 2$ & & $712 \mathrm{~Hz}$ \\
\hline 10 & $V+T$ & & $.852 \mathrm{~Hz}$ \\
\hline 11 & TA1 & & $.879 \mathrm{~Hz}$ \\
\hline 16 & TS2 & & $225 \mathrm{~Hz}$ \\
\hline 17 & LA1 & & $7.354 \mathrm{~Hz}$ \\
\hline 18 & $\mathrm{LA} 1+\mathrm{TS} 2$ & & $16 \mathrm{~Hz}$ \\
\hline 19 & $\mathrm{~V}+\mathrm{L}+\mathrm{T}$ & & $.746 \mathrm{~Hz}$ \\
\hline 20 & VA2 & & $59 \mathrm{~Hz}$ \\
\hline & KEY & & $\begin{array}{l}\cdots \cdots \text { East Lateral } \\
\text { - West Vertical } \\
\text { 一 East Vertical }\end{array}$ \\
\hline
\end{tabular}

$\mathrm{V}=$ vertical $\mathrm{L}=$ =lateral $\mathrm{T}=$ torsional $\mathrm{P}=$ =pylon; $\mathrm{S}=$ symmetric $\mathrm{A}=$ antisymmetric

Convention for development of displacements is given in Figure 6. 
Table 2 Bridge stay modes from ANSYS model

\begin{tabular}{|l|l|l|}
\hline frequency $/ \mathrm{Hz}$ & bridge stay no. & plane of vibration \\
\hline 2.751 & $\mathrm{sc} 9$ & horizontal \\
\hline 2.786 & $\mathrm{sc} 9$ & vertical \\
\hline 4.642 & $\mathrm{sc} 6$ & horizontal \\
\hline 4.665 & $\mathrm{sc} 6$ & vertical \\
\hline
\end{tabular}


Table 3 Stay cable fundamental frequencies and estimated tensions

\begin{tabular}{|c|c|c|c|c|c|c|c|}
\hline \multirow[t]{2}{*}{ cable } & \multirow{2}{*}{$\begin{array}{l}\text { elev- } \\
\text { ation } \\
\rho^{\circ}\end{array}$} & \multirow{2}{*}{$\begin{array}{l}\text { fundamental } \\
\text { frequency } \\
\mathrm{f} / \mathrm{Hz}\end{array}$} & \multicolumn{3}{|c|}{ Simple estimate } & \multirow{2}{*}{\begin{tabular}{|l} 
Refined estimate \\
tension \\
$\mathrm{T} / \mathrm{kN}$ \\
\end{tabular}} & \multirow{2}{*}{\begin{tabular}{|l} 
measured \\
tension \\
$\mathrm{T} / \mathrm{kN}$ \\
\end{tabular}} \\
\hline & & & $\begin{array}{l}\text { length } \\
\mathrm{L} / \mathrm{m}\end{array}$ & $\begin{array}{l}\text { steel mass } \\
\mathrm{m} / \mathrm{kg}^{-\mathrm{m}^{-1}}\end{array}$ & $\begin{array}{l}\text { tension } \\
\mathrm{T} / \mathrm{kN} \\
\end{array}$ & & \\
\hline $\mathrm{sc1}$ & 48.98 & 2.35 & 43.17 & 50.41 & 2075 & 3650 & 2983 \\
\hline $\mathrm{sc} 2$ & 57.01 & 2.78 & 37.76 & 45.62 & 2010 & 3536 & 2552 \\
\hline $\mathrm{sc} 3$ & 71.39 & 3.26 & 32.52 & 45.62 & 2049 & 3553 & 2293 \\
\hline sc4 & 90 & 3.59 & 29.33 & 45.62 & 2029 & 3462 & 2317 \\
\hline sc5 & 70.73 & 3.56 & 30.61 & 45.62 & 2161 & 3714 & 2465 \\
\hline sc6 & 56.02 & 2.99 & 35.67 & 45.62 & 2069 & 3612 & 2650 \\
\hline sc7 & 45.55 & 2.51 & 42.52 & 45.62 & 2080 & 3675 & 3020 \\
\hline$s c 8$ & 38.20 & 2.21 & 50.40 & 50.41 & 2500 & 4227 & 3476 \\
\hline sc9 & 32.91 & 1.99 & 58.87 & 50.41 & 2754 & 4733 & 3944 \\
\hline bs a1 & \multirow[t]{2}{*}{30.74} & 1.51 & \multirow[t]{2}{*}{62.38} & \multirow[t]{2}{*}{76.82} & 2719 & 4865 & 4038 \\
\hline bs a2 & & 1.57 & & & 2947 & 5273 & 4063 \\
\hline bs b1 & \multirow[t]{2}{*}{33.16} & 1.58 & \multirow[t]{2}{*}{59.69} & \multirow[t]{2}{*}{76.82} & 2734 & 4872 & 4088 \\
\hline bs b2 & & 1.57 & & & 2699 & 4811 & 4088 \\
\hline bs c1 & \multirow[t]{2}{*}{37.10} & 1.60 & \multirow[t]{2}{*}{58.90} & \multirow[t]{2}{*}{76.82} & 2729 & 4859 & 4360 \\
\hline bs c2 & & 1.60 & & & 2729 & 4859 & 4385 \\
\hline
\end{tabular}



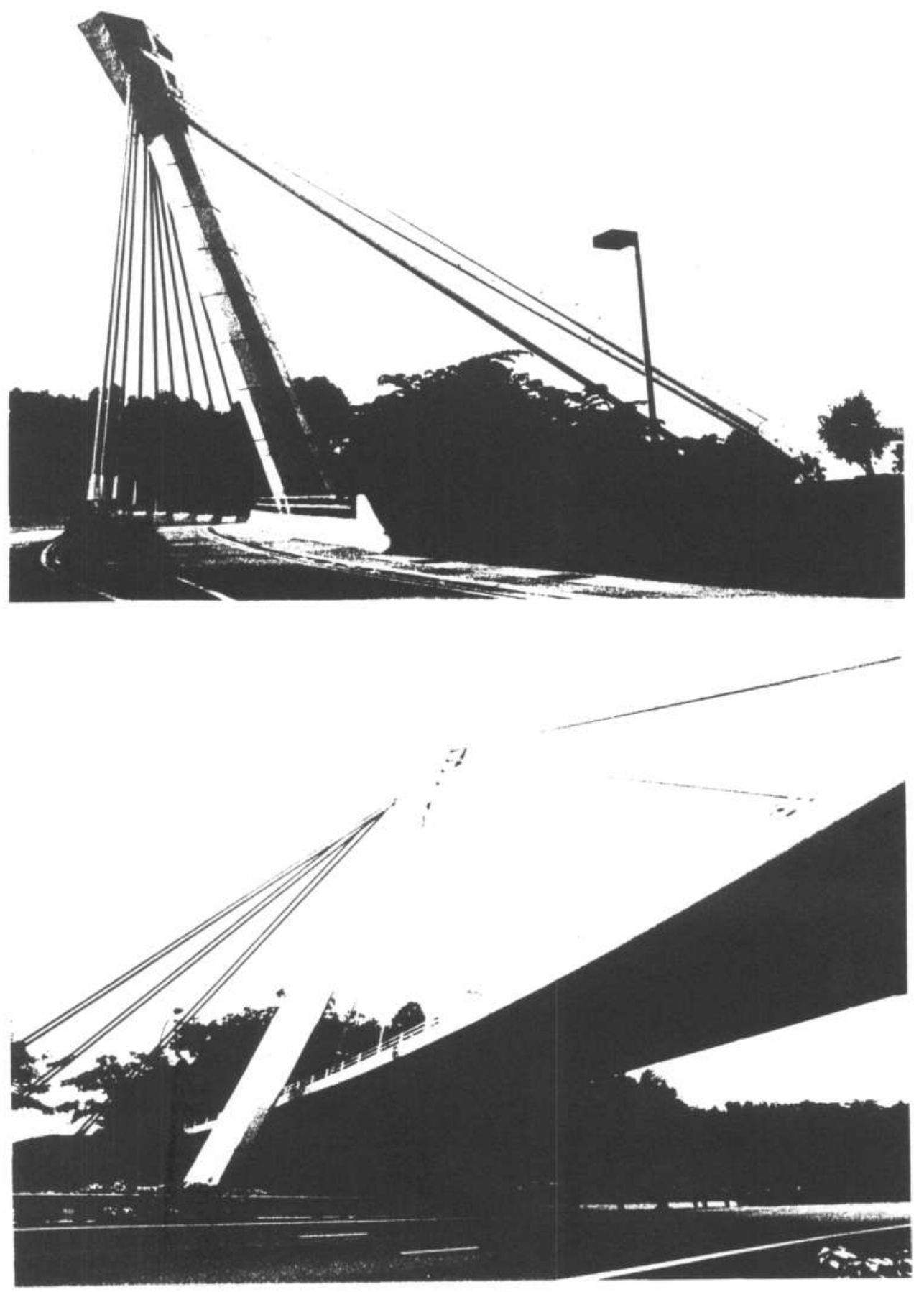

Figure 1 Safti Link Bridge 

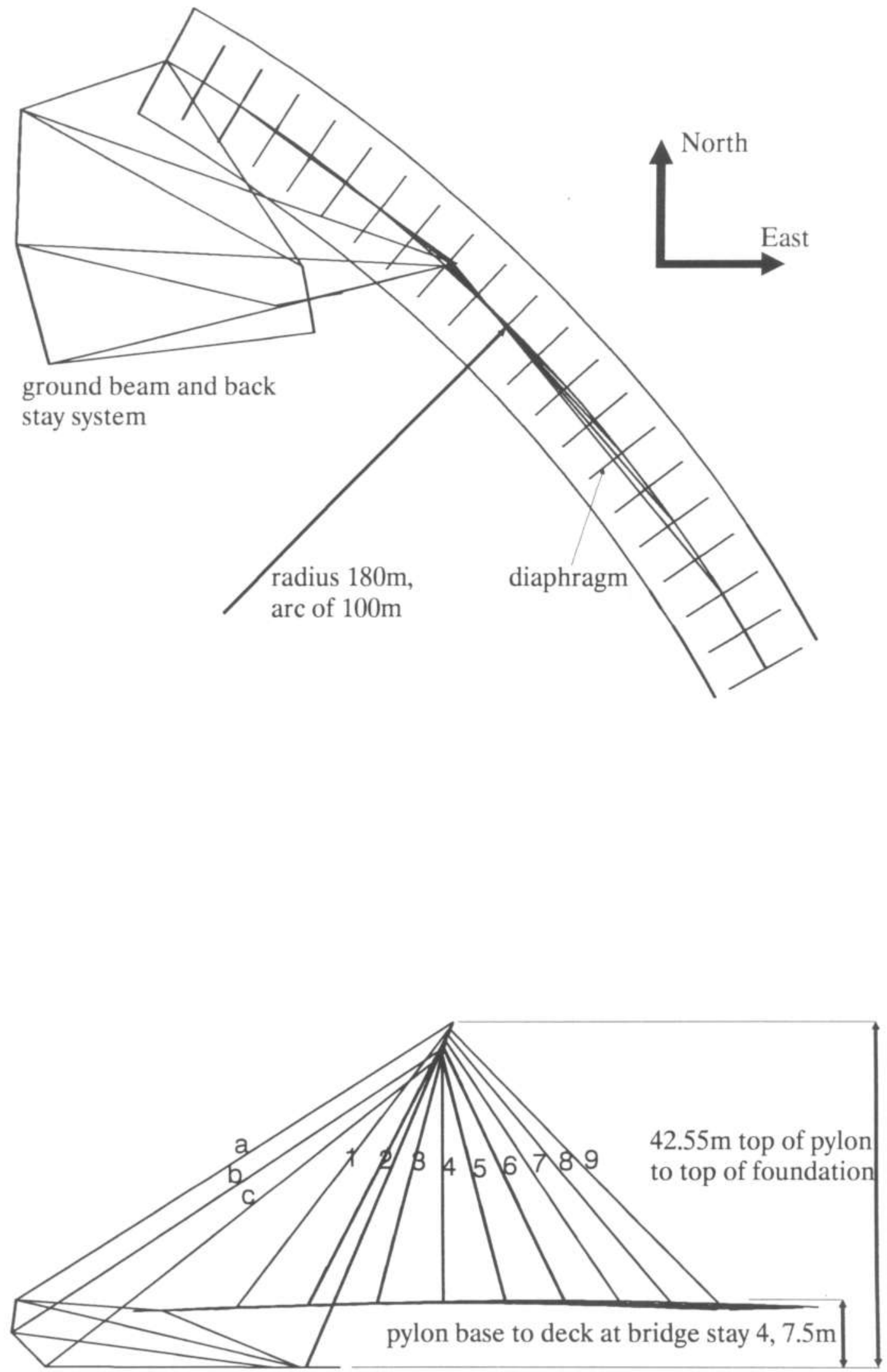

Figure 2 Schematic plan and elevation of SAFTI Link Bridge.

Bridge stays are numbered 1 to 9 , back stay (cable pairs) are a,b,c 


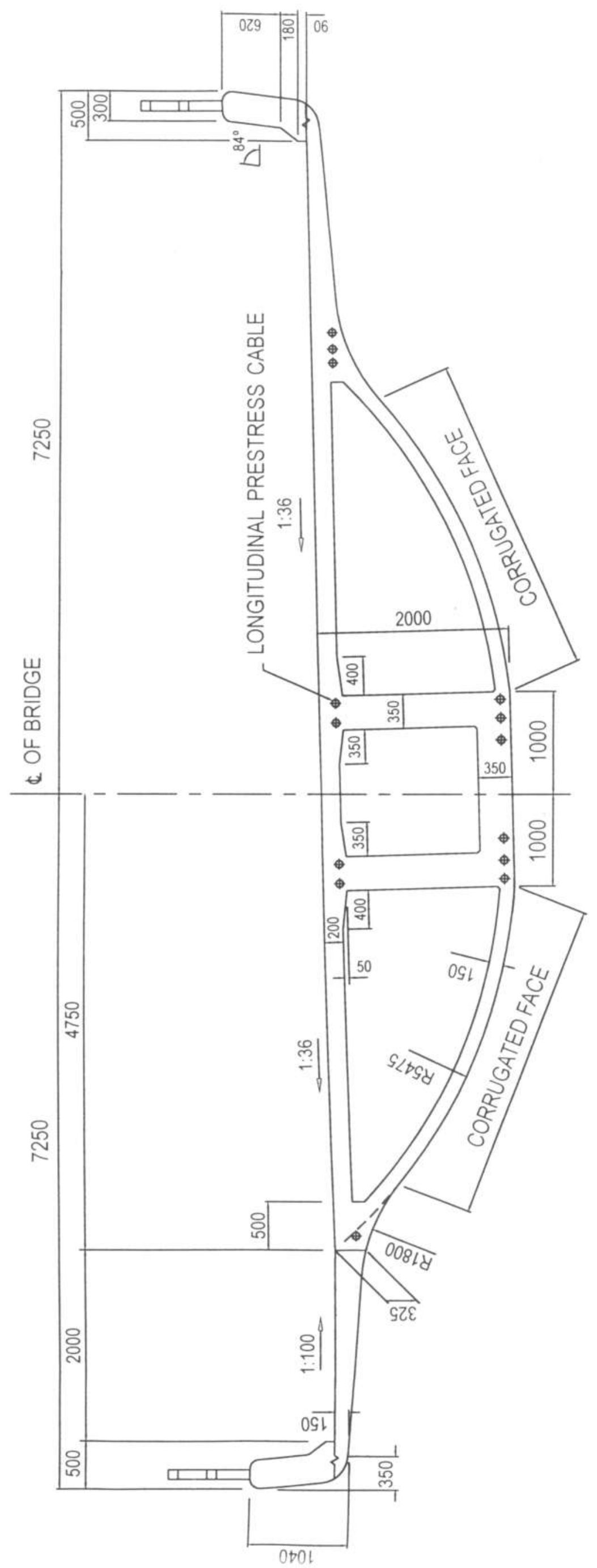

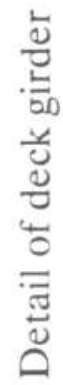

先 


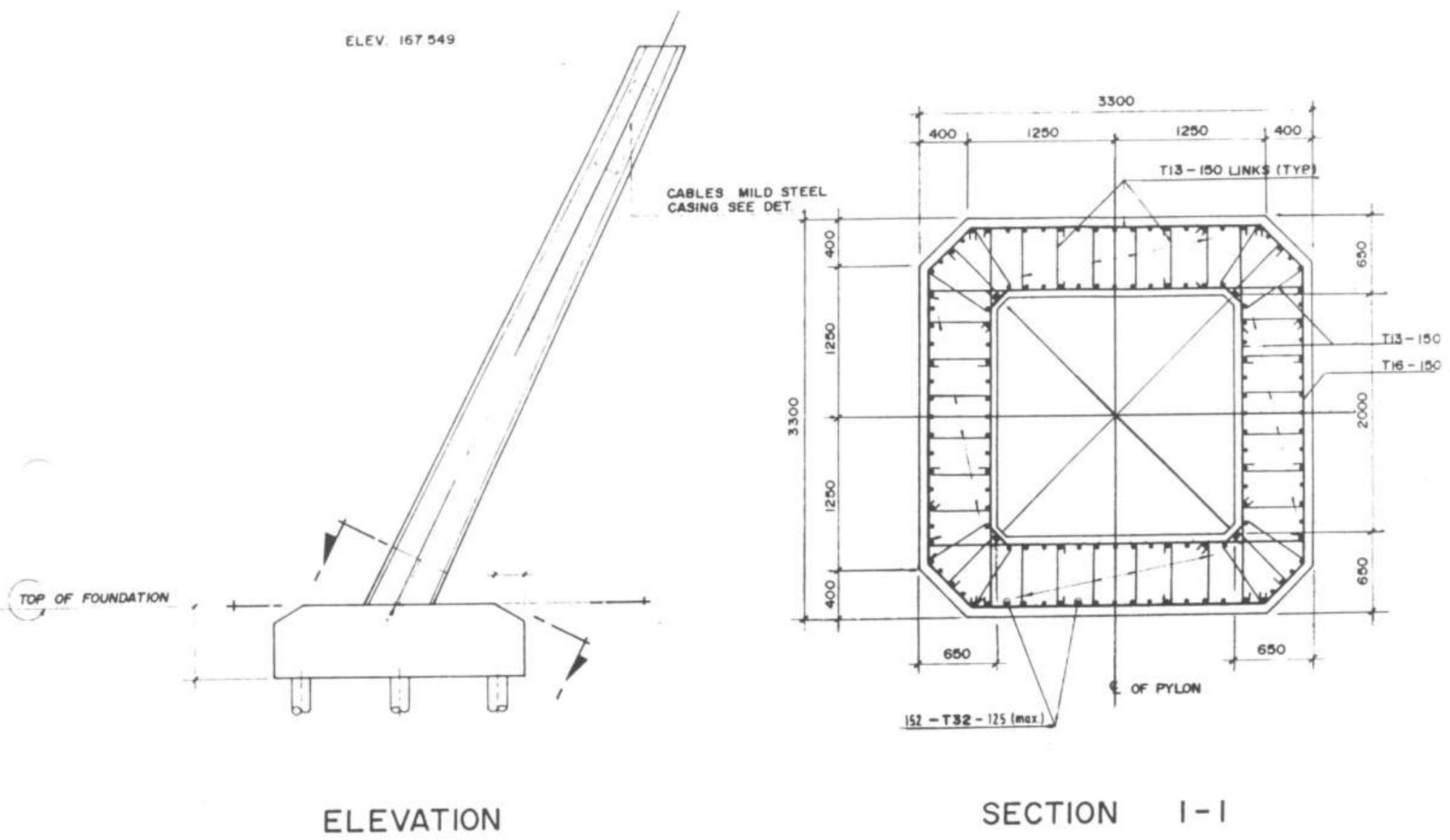

Figure 4 Detail of pylon. Top of foundation is at $125.000 \mathrm{~m}$ 


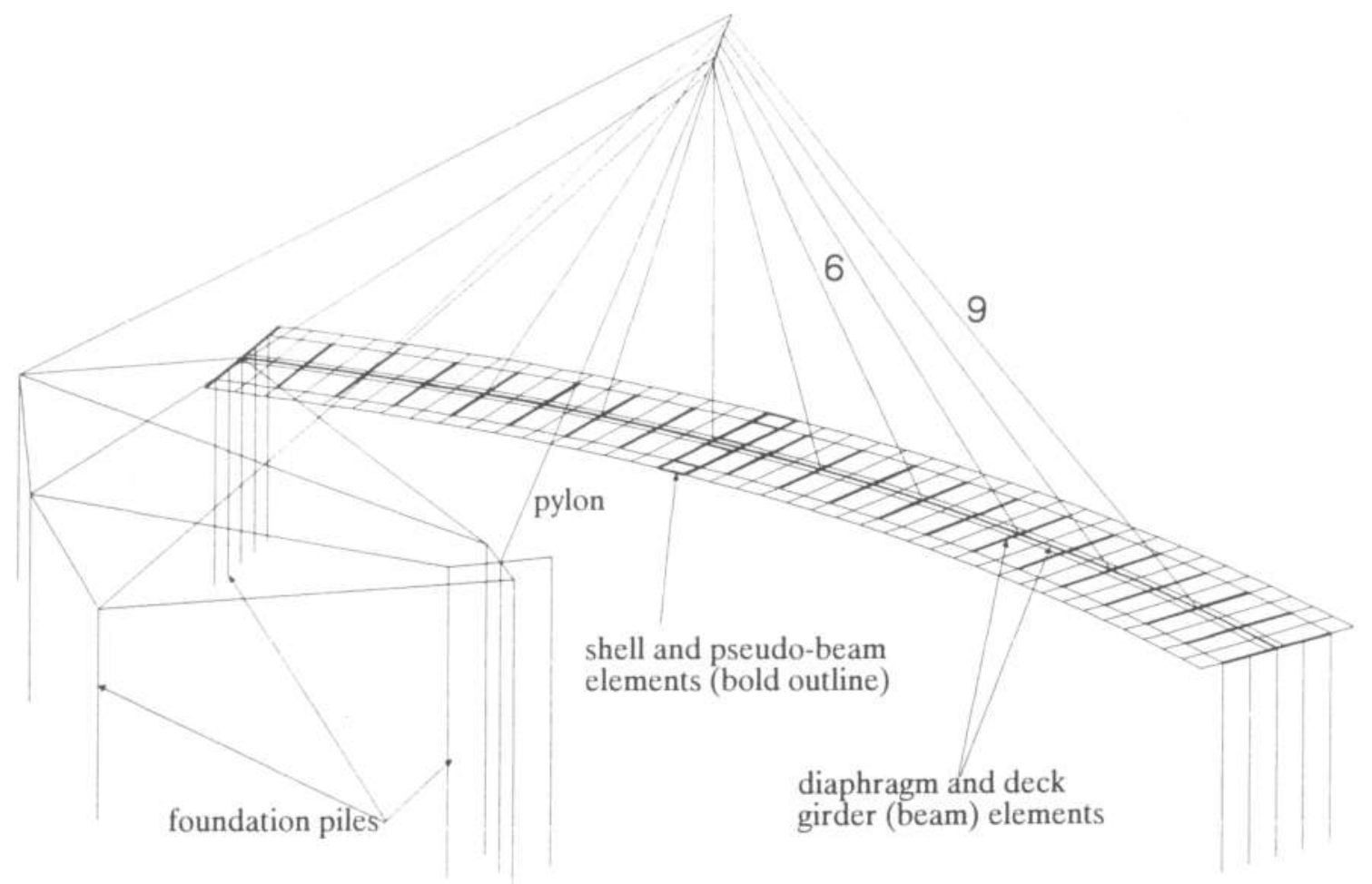

Figure $5 \quad$ Finite element model

(i) deck girder with diaphragms (bold)

(ii) ground beam, pylon, back stays, bridge stays and foundation piles

(iii) pseudo-beams and shell elements; 1 set of these is shown bold 

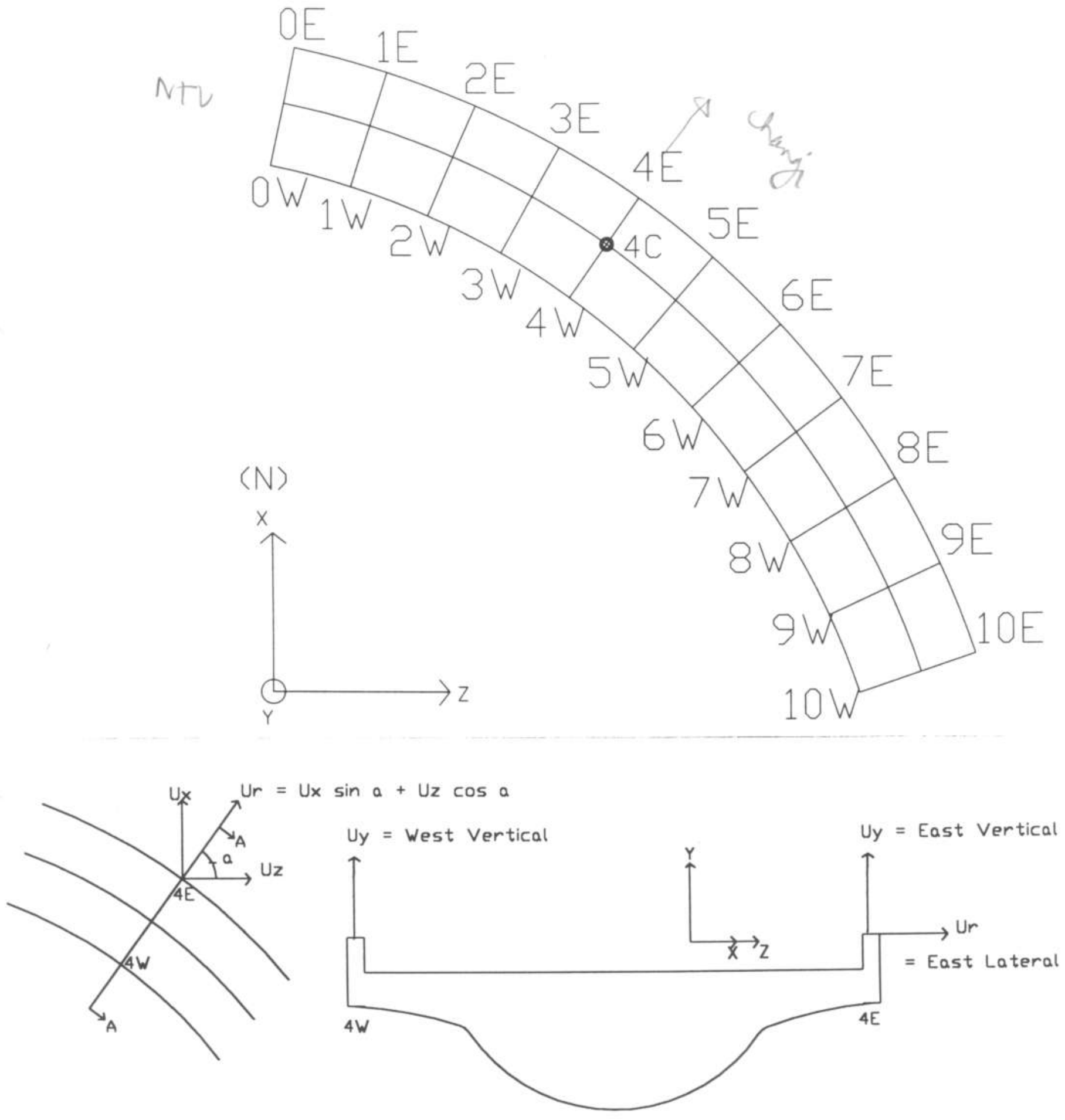

SECTION A-A

Figure 6 Development of deck for display of radial and vertical mode components 


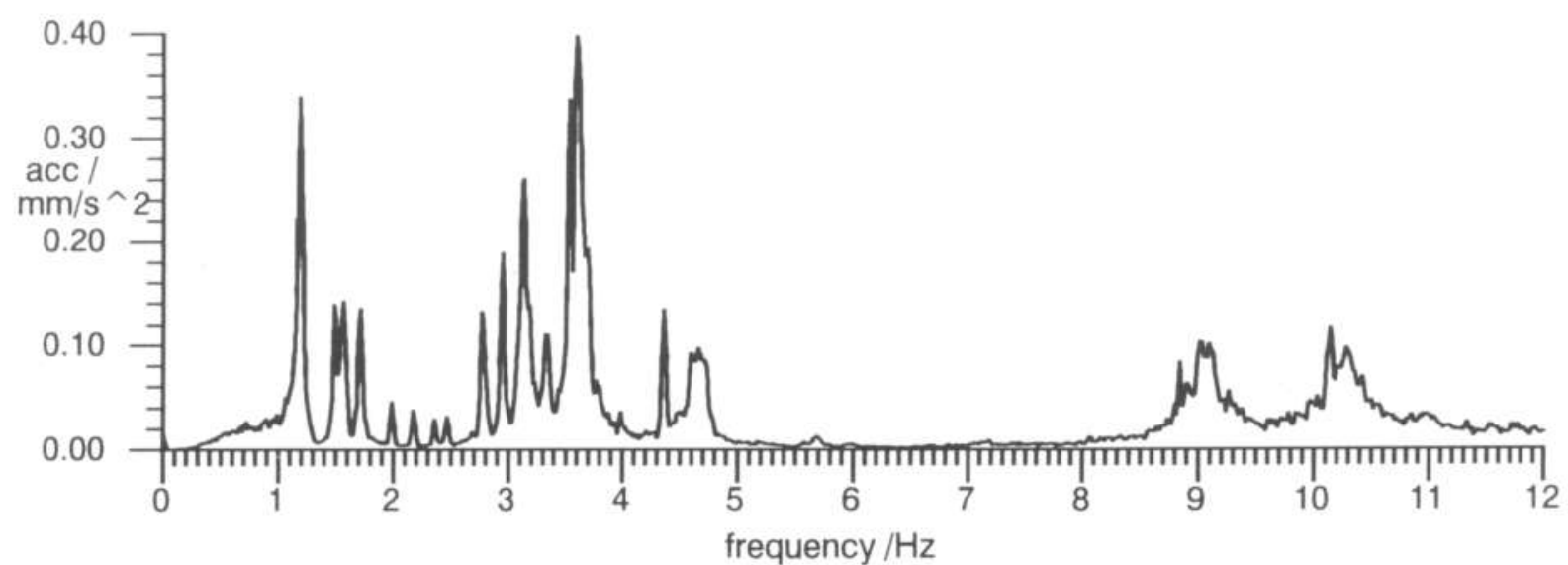

a) Ambient vibrations due to wind

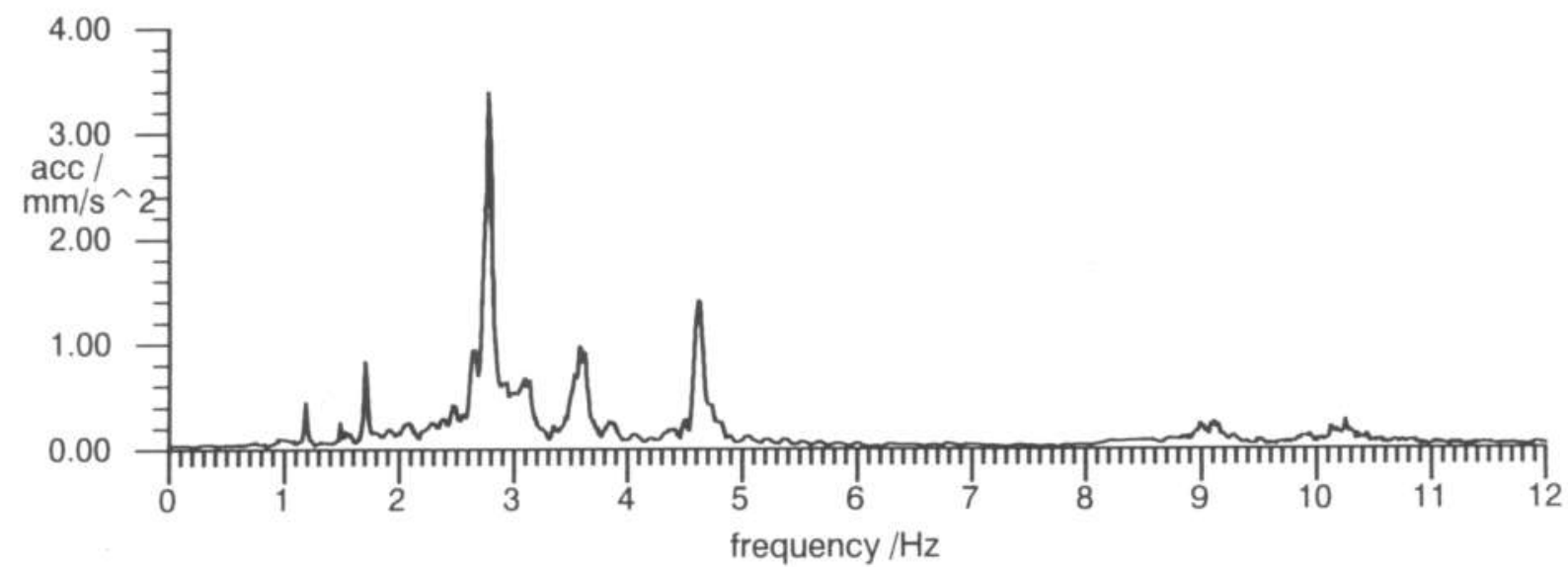

b) Ambient vibrations due to heavy vehicle crossing

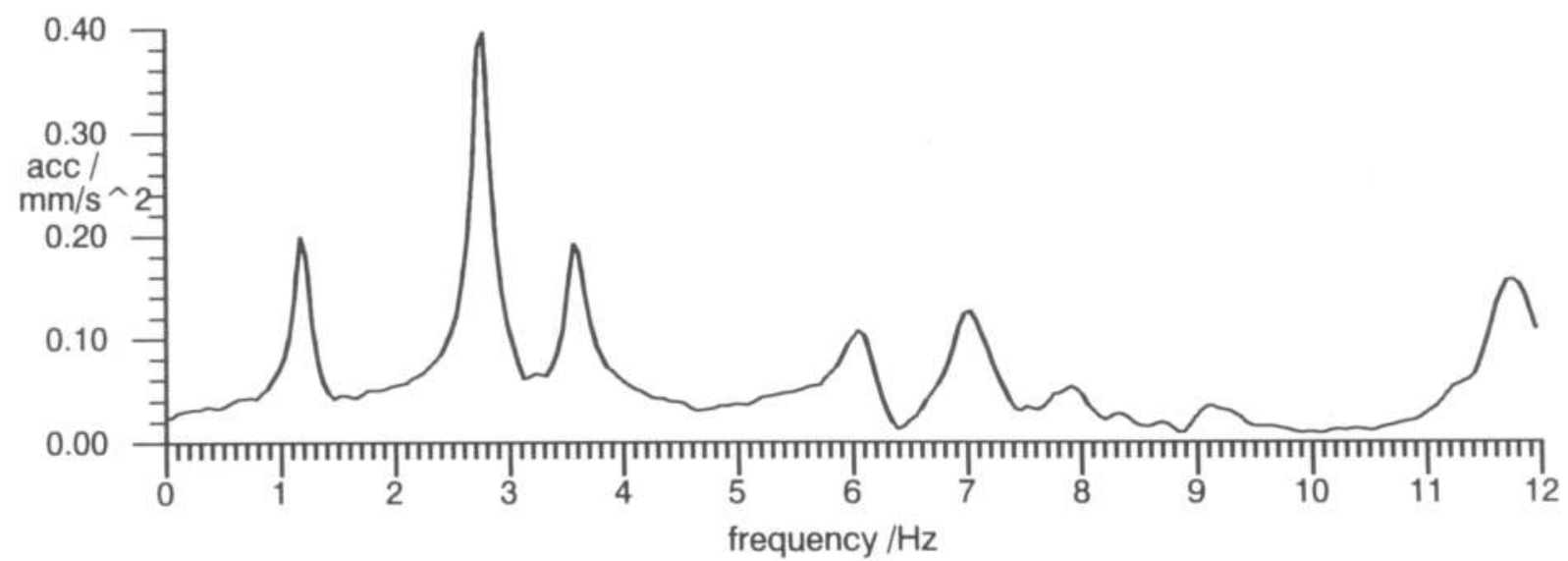

c) Forced vibrations due to hammer impact

Figure 7 Deck vertical acceleration response auto power spectra for different types of excitation 


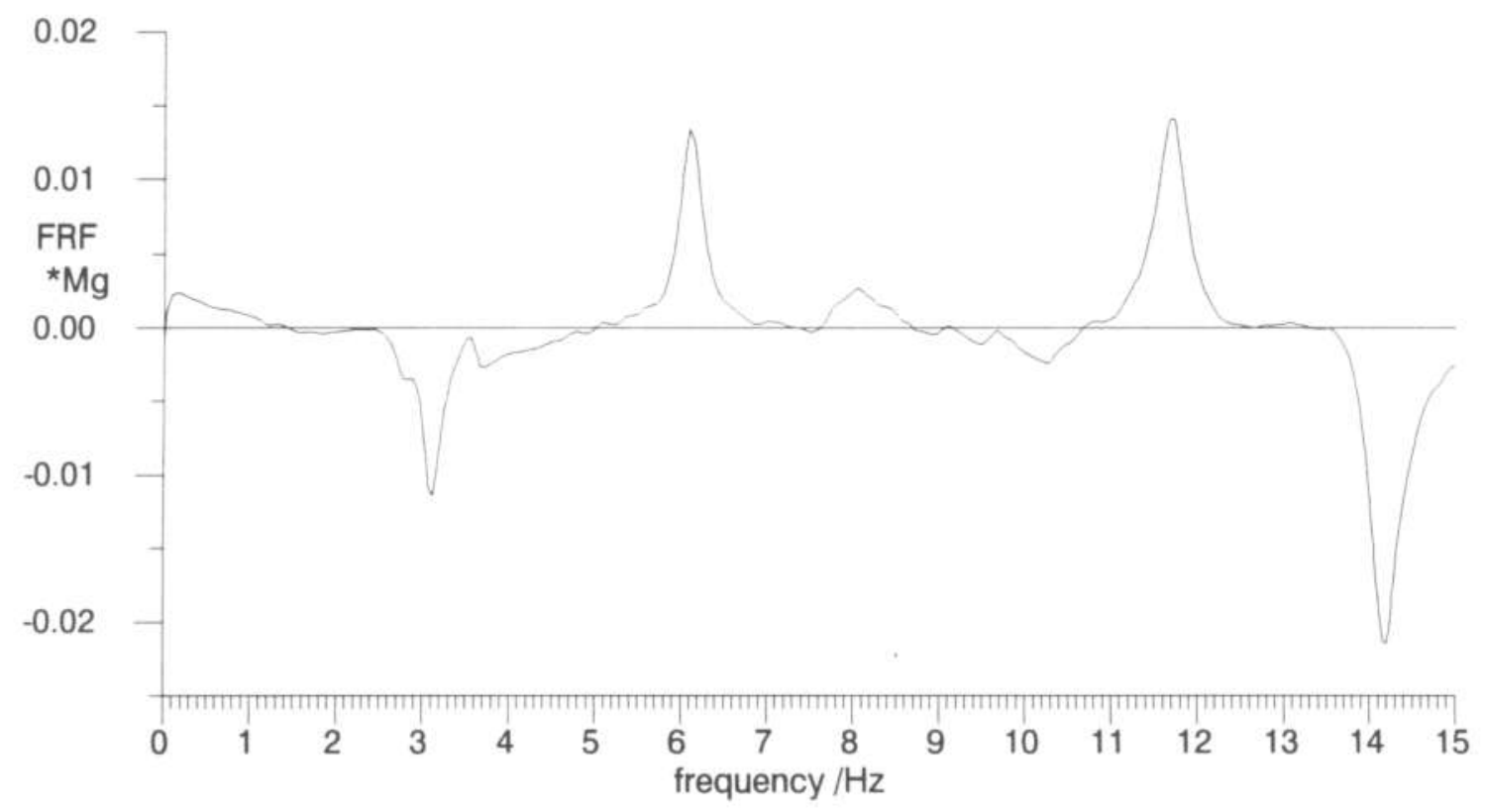

Figure 8 Imaginary part of frequency response function (FRF) for lateral acceleration at $7 \mathrm{E}$ and hammer impact between $3 \mathrm{E}$ and $4 \mathrm{E}$. Units of FRF are (mass) ${ }^{-1}$ 


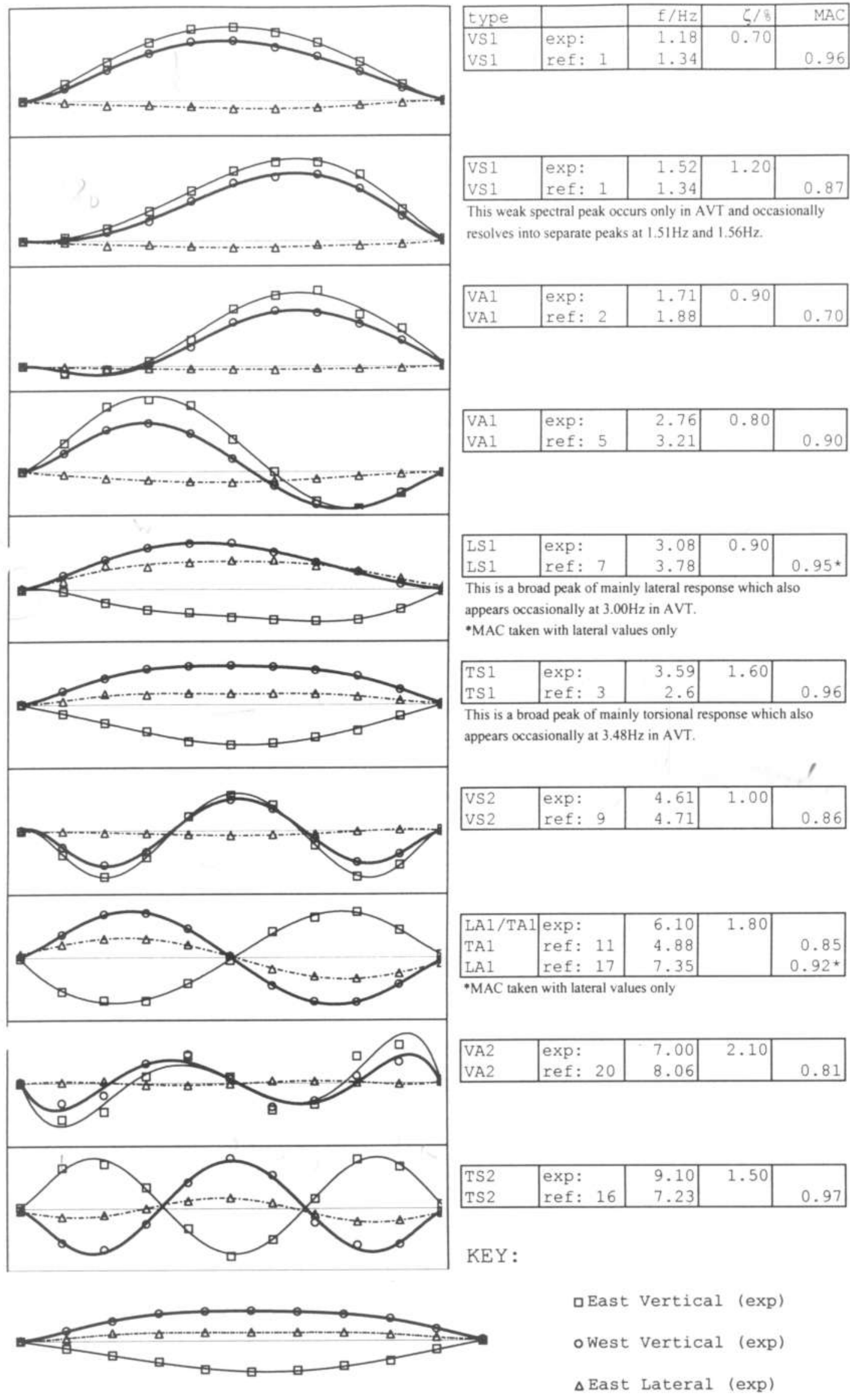

Figure 9 Experimental modes and comparison with FE modes. The plots show the experimental mode shapes.

The experimental mode frequencies (exp) and corresponding values and mode numbers from the finite element reference model (ref) are given alongside together with MAC values and experimental damping ratios 


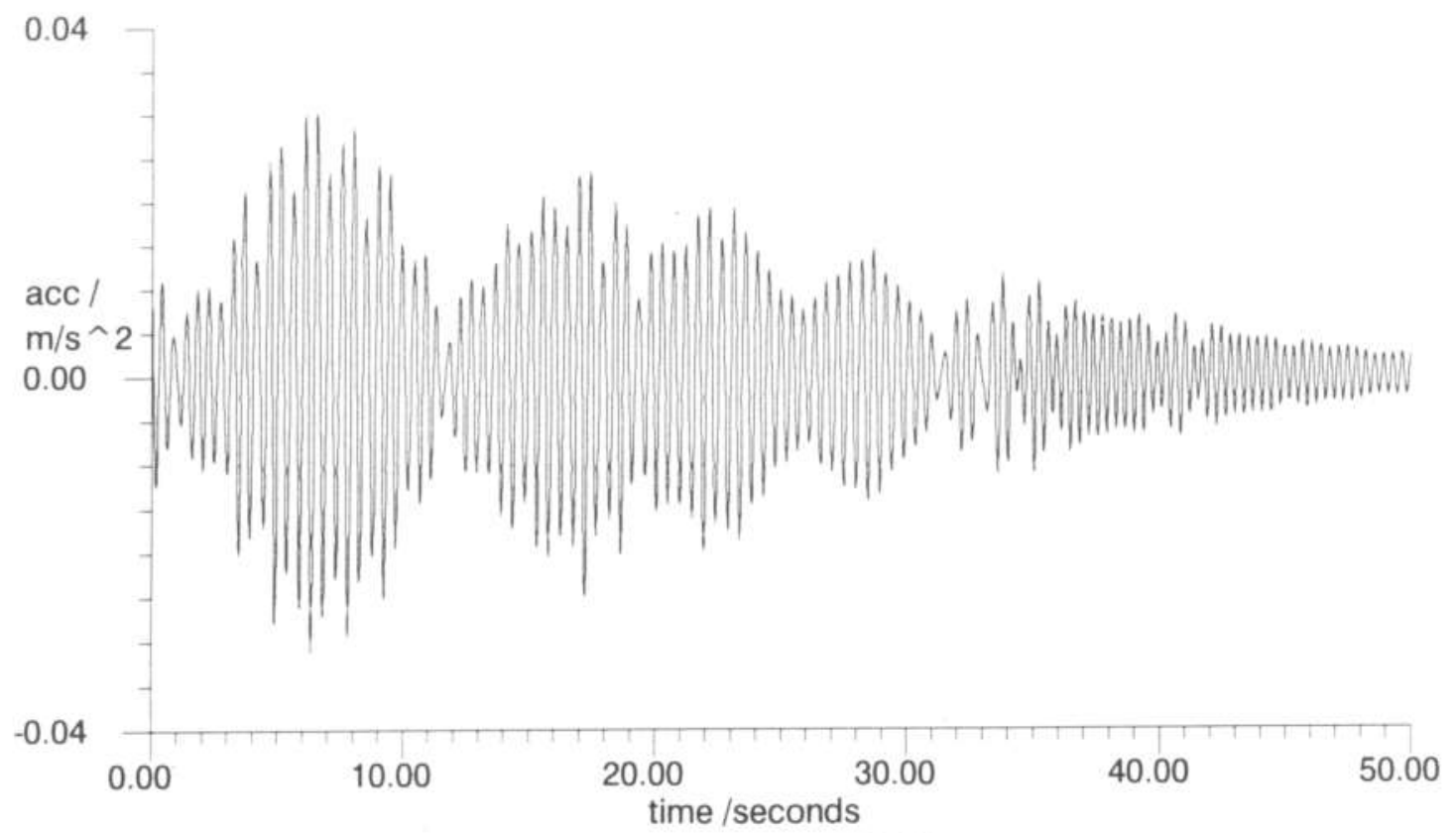

a) Response due to soldiers marching across bridge

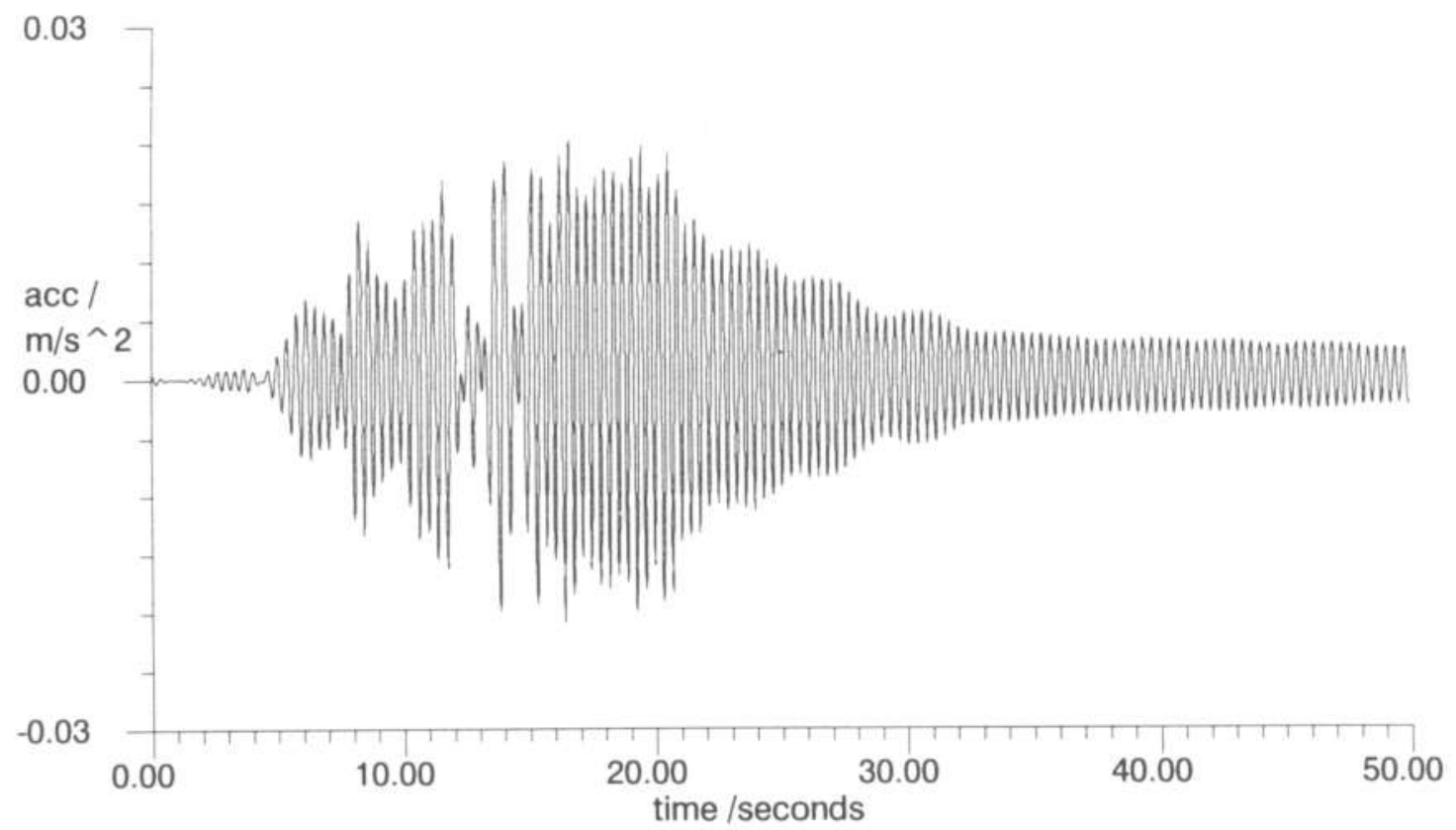

b) Response due to heavy vehicle crossing bridge

Figure 10 Bandpass filtered vertical acceleration response of deck at $3 \mathrm{E}$ 

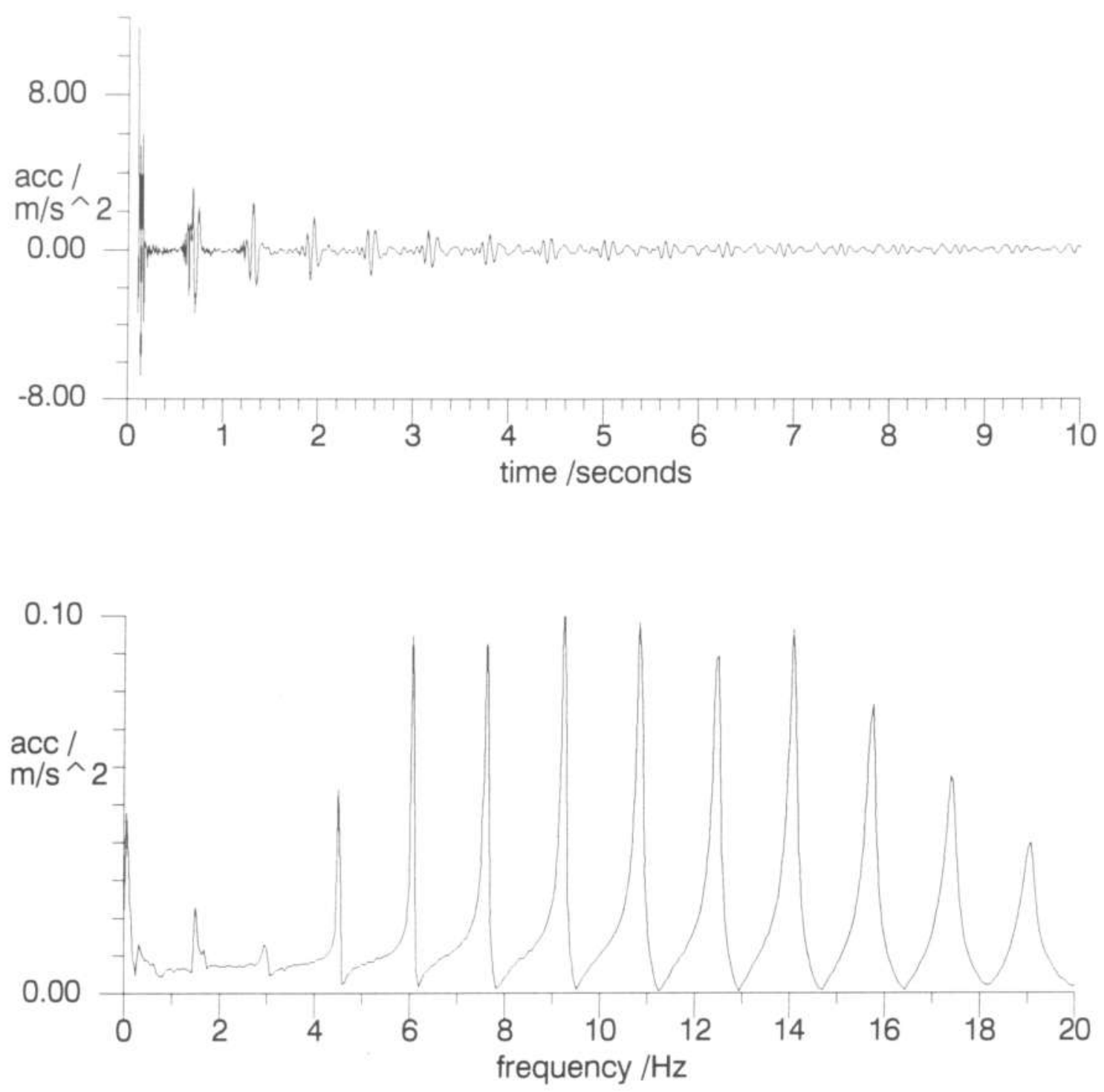

Figure 11 Transverse acceleration response of back stay cable a1 to hammer impact. Time history (upper) and correspondinga auto power spectrum (lower) 